\title{
Effects of nutritional status and gonadal steroids on expression of appetite-regulatory genes in the hypothalamic arcuate nucleus of sheep
}

\author{
Z A Archer, P A Findlay, S R McMillen ${ }^{1}$, S M Rhind ${ }^{1}$ \\ and $\mathbf{C} \mathbf{L}$ Adam \\ Energy Balance and Obesity Division, Rowett Research Institute, Bucksburn, Aberdeen AB21 9SB, UK \\ ${ }^{1}$ Macaulay Institute, Craigiebuckler, Aberdeen AB15 8QH, UK \\ (Requests for offprints should be addressed to C L Adam; Email: cla@rri.sari.ac.uk)
}

\begin{abstract}
Sheep exhibit photoperiod-driven seasonal changes in appetite and body weight so that nutritional status increases in long days (LD) and decreases in short days (SD); additionally, they are reproductively active in SD and inactive in LD. We addressed the hypothesis that appetite-regulatory genes in the hypothalamus respond differently to changes in nutritional feedback induced by photoperiod as opposed to food restriction, and that responses would be influenced by gonadal steroid status. Castrated oestradiol-implanted male sheep were kept in SD (8 h light/day) or LD (16 h light/day) for 11 weeks, with ad libitum or restricted food (experiment $1 ; n=8$ / group). Rams were kept in SD or LD for 12 weeks with ad libitum or restricted food (experiment $2 ; n=6$ /group). Gene expression (by in situ hybridisation) in the hypothalamic arcuate nucleus for leptin receptor (OB-Rb), neuropeptide Y (NPY), pro-opiomelanocortin (POMC) and agouti-related peptide (AGRP) was unaffected by
\end{abstract}

photoperiod treatment, but food restriction increased NPY and AGRP mRNAs, in experiment 1 . In experiment 2, mRNAs for POMC and cocaine- and amphetamineregulated transcript (CART) were up-regulated and AGRP down-regulated in $\mathrm{SD}$, while food restriction increased OB-Rb mRNA, increased NPY and AGRP mRNAs only in LD and decreased POMC mRNA only in SD. Thus, gene expression responded differently to photoperiod and food restriction, and the melanocortin pathway was up-regulated in SD in reproductively activated rams but not in oestradiol-implanted castrates. These data support the hypothesis that hypothalamic appetiteregulatory pathways respond differently to changes in nutritional feedback induced by photoperiod as opposed to food restriction, with gonadal steroid feedback additionally influencing the responses.

Journal of Endocrinology (2004) 182, 409-419

\section{Introduction}

Recent advances in our understanding of nutritional signalling to the brain in the regulation of appetite and energy balance have recognised the importance of circulating leptin and its primary target pathways in the hypothalamic arcuate nucleus (ARC) (Ahima et al. 2000). The majority of studies have employed an imposed dietary or energetic challenge that elicits a 'compensatory' response in the animal in order to correct the energy imbalance. However, seasonal animals like sheep also exhibit programmed 'anticipatory' changes in voluntary food intake (VFI) and body weight (BW) in response to annual changes in photoperiod, without any imposed energetic perturbation (Mercer et al. 2000a). Thus appetite and $\mathrm{BW}$ increase in sheep kept in long-day photoperiod and decrease in sheep kept in short-day photoperiod
(Lincoln \& Richardson 1998, Adam 2000). The reproductive neuroendocrine axis is also responsive to annual changes in photoperiod, with activation in short days and inhibition in long days (Lincoln \& Short 1980), and it is inhibited during food or growth restriction (I'Anson et al. 1991). Thus, both the appetite and reproductive axes are regulated within the hypothalamus where both are sensitive to nutritional as well as to photoperiodic feedback. However, since photoperiod itself drives changes in nutritional feedback, there is clearly important interaction between these two hypothalamic inputs. Indeed, seasonal changes in the sensitivity of the appetite and reproductive neuroendocrine axes to the anorexigenic hormone, leptin, administered into the third cerebral ventricle have been reported (Clarke et al. 2001, Miller et al. 2002).

Localisation and sensitivity of gene expression to imposed changes in energy balance have been demonstrated 
in sheep for critical hypothalamic receptors and appetiteregulating neuropeptides targeted by leptin (Henry et al. 2000, 2001, Adam et al. 2002, Archer et al. 2002). These are notably the genes encoding the leptin receptor (OB-Rb), neuropeptide Y (NPY) and agouti-related peptide (AGRP), which are up-regulated in the ARC during negative energy balance, and pro-opiomelanocortin (POMC) and cocaine- and amphetamine-related transcript (CART), which show no significant change. However, their sensitivity to a voluntary photoperiod-induced reduction in nutritional status as opposed to imposed negative energy balance has yet to be fully resolved. A recent study has reported higher ARC levels of OB-Rb, NPY and AGRP mRNAs, and lower amounts of POMC mRNA, in long-day hyperphagic rams than in short-day hypophagic rams, indicating photoperiodic regulation of these genes (Clarke et al. 2003). Here, we used photoperiod as a tool to alter the nutritional status of our sheep and included comparative food restriction treatments within the same study. The data further complement those of Clarke et al. (2003) by virtue of differences in experimental design: i.e. a shorter duration of photoperiod exposure, examining responses in both rams and steroidclamped castrates and increasing the number of ARC neuropeptide mRNAs studied.

In this study, nutritional status was adjusted by subjecting sheep to long-day or short-day photoperiod, with ad libitum (AL) or restricted (R) food. We assessed the level of nutritional feedback from endocrine metabolic status, measuring circulating leptin and other putative nutritional messengers such as insulin. We assessed the hypothalamic response to nutritional feedback in terms of VFI (where appropriate), pulsatile luteinizing hormone (LH) secretion (gonadotrophin-releasing hormone $(\mathrm{GnRH})$ by inference, Clarke \& Cummins 1982) and expression of nutritionally sensitive hypothalamic genes. Sheep of the Soay breed were used since their responses to photoperiod are especially pronounced. Typically, appetite and gonadotrophin responses to an abrupt change in photoperiod emerge after 4 weeks and full expression of the divergent photoperiodic phenotypes is seen after 8-12 weeks (Lincoln \& Richardson 1998, Adam 2000); we therefore used periods of 11-12 weeks of photoperiod exposure in the present experiments.

The amplitude of photoperiod-induced appetite cycles is greater in rams than in castrates (Kay 1985). Since testosterone concentrations show photoperiodic variation in line with seasonal breeding (Lincoln \& Davidson 1977), this indicates that changes in gonadal steroid concentrations may influence hypothalamic appetite drive. Changes in gonadal steroid feedback also influence nutritional feedback effects on hypothalamic GnRH output, given that the suppression of LH in sheep by chronic food restriction is amplified in the presence of oestradiol (Foster \& Olster 1985, Beckett et al. 1997). We therefore assessed the contribution of concurrent alterations in gonadal steroid status to the observed responses to alterations in nutritional status in the present study. Gonadal steroid feedback was either clamped at a constant physiological level (using oestradiol-implanted castrates) in the first experiment, or allowed to free-run and change with the photoperiods by using rams in the second experiment.

These experiments addressed the hypothesis that the ovine hypothalamus responds differently to photoperiodinduced changes in nutritional feedback as opposed to experimentally imposed food restriction in terms of gene expression for primary leptin targets in the hypothalamus, and that these responses are influenced by gonadal steroid feedback.

\section{Materials and Methods}

All procedures were licensed under the Animals (Scientific Procedures) Act 1986 and received prior approval from the relevant local Ethical Review Committee.

\section{Animals and treatments}

Experiment 1 Castrated adult male sheep of the Soay breed, initial BW $33.3 \pm 0.80 \mathrm{~kg}$ and body condition score (BCS) $2 \cdot 3 \pm 0.02$ (scale: $0=$ emaciated to $5=$ obese; Russel et al. 1969), were housed individually at Glensaugh Research Station $\left(57^{\circ} \mathrm{N}\right)$ in October 1997, i.e. from a background of shortening natural photoperiod in the autumn. Two weeks before the start of experiment 1 each sheep received subcutaneously two Silastic oestradiolcontaining implants made from Silastic tubing with an external diameter of $4.8 \mathrm{~mm}$ (Osteotec Ltd, Christchurch, Dorset, $(\mathrm{UK})$ and each containing a $15 \mathrm{~mm}$ packed column of 17 $\beta$-oestradiol (Sigma UK, Poole, Dorset, UK) (after Adam \& Findlay 1998); this raised circulating oestradiol concentrations to a steady $4 \cdot 0 \pm 0 \cdot 20 \mathrm{pg} / \mathrm{ml}$ (measured by the RIA of Mann et al. 1995), as designed to be equivalent to physiological values seen in ewes in the luteal phase of the oestrous cycle (Goodman 1994). For 11 weeks sheep were exposed to either short-day (SD; $8 \mathrm{~h}$ light:16 h darkness) or long-day (LD; $16 \mathrm{~h}$ light:8 $\mathrm{h}$ darkness) artificial photoperiods ( $n=16$ per photoperiod). Daily at $0830 \mathrm{~h}$ they were given a complete diet ('Soay mix'; North Eastern Farmers, Bannermill, Aberdeen, UK, containing $40 \%$ bruised barley and 35\% dried grass pellets as the main ingredients, and $11.6 \mathrm{MJ}$ metabolizable energy (ME) $\mathrm{kg} /$ dry matter (DM)). Within each photoperiod, half were fed AL, with a refusal margin of at least $10 \%$, and half were fed an amount restricted (R) to $50 \%$ requirements for $\mathrm{BW}$ maintenance $\left(0 \cdot 42 \mathrm{MJ} \mathrm{ME} / \mathrm{kg} \mathrm{BW} \mathrm{BW}^{0.75}\right.$; Robinson 1983). BW and BCS were measured weekly and VFI was recorded on 5 days of each week (Monday to Friday) by weighing residues before introducing fresh food. 
Experiment 2 Adult rams of the Soay breed, initial BW $27 \cdot 0 \pm 1 \cdot 01 \mathrm{~kg}$, were housed individually at Duthie Experimental Farm $\left(57^{\circ} \mathrm{N}\right)$ in May 2000. For 16 weeks prior to the experiment they were exposed to either SD or LD ( $n=12$ per photoperiod) and fed AL. The photoperiods were then reversed for the 12-week experiment. By virtue of the preceding photoperiod, initial $\mathrm{BW}$ at this stage was $34.6 \pm 1.19 \mathrm{~kg}$ in SD and $31.0 \pm 0.89 \mathrm{~kg}$ in LD; half in each photoperiod were fed AL with a minimum refusal margin of $10 \%$ and half were fed an amount restricted (R) to $70-100 \%$ requirements for $\mathrm{BW}$ maintenance. The maintenance requirement was calculated for the actual or predicted SD asymptotic BW for each sheep, equating to $100 \%$ maintenance for the rams transferred from SD to $\mathrm{LD}$, and $70 \%$ for the rams transferred from LD to SD (effectively increasing to $100 \%$ as these sheep lost BW). They were fed twice daily at $0800 \mathrm{~h}$ and $1600 \mathrm{~h} \mathrm{a}$ complete diet (containing 50\% chopped hay and 30\% bruised barley as the main ingredients, and $10 \mathrm{MJ} \mathrm{ME}$ $\mathrm{kg} / \mathrm{DM})$. BW and BCS were measured weekly and VFI was recorded daily.

\section{Tissue collection}

Blood samples were collected by jugular venipuncture twice weekly before feeding (experiment 1) or weekly at $2 \mathrm{~h}$ after feeding (experiment 2). Plasma was stored at $-20{ }^{\circ} \mathrm{C}$ prior to analysis for insulin, leptin, glucose and non-esterified fatty acids (NEFA). On the last or penultimate day before they were killed, blood samples were collected via temporary jugular catheters every $15 \mathrm{~min}$ for $8 \mathrm{~h}$, starting at lights-on, and plasma was stored at $-20^{\circ} \mathrm{C}$ for subsequent $\mathrm{LH}$ analysis.

The sheep were killed by a lethal i.v. dose of sodium pentobarbitone (Euthatal; Rhone Merieux Ltd, Harlow, Essex, UK) between $0830 \mathrm{~h}$ and $1630 \mathrm{~h}$ on 2 consecutive days in both experiments. One animal was killed from each group in turn in order to minimise any time of day effect on mean post-mortem results. The brain was excised, flash frozen in isopentane over dry ice and stored at $-80{ }^{\circ} \mathrm{C}$. In addition, testes were removed and weighed in experiment 2 .

\section{Plasma analyses}

Plasma concentrations of glucose and NEFA were determined by automated analysis, with sensitivity and intra- and interassay coefficients of variation (CV) of $0.04 \mathrm{mmol} / \mathrm{l}$, $2.0 \%$ and $4.0 \%$ respectively for NEFA, and $0.34 \mathrm{mmol} / \mathrm{l}$, $0 \cdot 35 \%$ and $2 \cdot 3 \%$ respectively for glucose. Leptin concentrations were determined by homologous RIA (Marie et al. 2001) with sensitivity $0.5 \mathrm{ng} / \mathrm{ml}$, intra-assay CV $12 \cdot 0 \%$ and interassay CV 16\%. The RIA for insulin (MacRae et al. 1991) had sensitivity $0 \cdot 2 \mu \mathrm{IU} / \mathrm{ml}$, intra-assay $\mathrm{CV}$ $4 \cdot 7 \%$ and interassay CV $4 \cdot 9 \%$. Finally, LH was measured by RIA (McNeilly et al. 1986) with sensitivity $0.05 \mathrm{ng} / \mathrm{ml}$ and intra- and interassay CV $7 \cdot 9 \%$ and $9 \cdot 3 \%$ respectively.

\section{In situ hybridisation}

Coronal cryostat sections $(20 \mu \mathrm{m})$ of hypothalamic tissue were thaw-mounted onto slides double-coated with gelatin and poly-L-lysine, and stored at $-80{ }^{\circ} \mathrm{C}$. Gene expression for OB-Rb, NPY, AGRP, POMC and CART was measured by in situ hybridisation, using techniques described in detail and fully validated elsewhere (Mercer et al. 1995, Adam et al. 1997). A 308 bp riboprobe complementary to fragments of the intracellular domain of $\mathrm{OB}-\mathrm{Rb}$ was generated from a cloned sheep cDNA as described previously (Mercer et al. 1998). The NPY probe was generated from a $500 \mathrm{bp}$ fragment of rat prepro-NPY cDNA and has been validated for use on sheep tissues (Adam et al. 1997). The CART probe (used only in experiment 2) was generated from a cloned sheep $299 \mathrm{bp}$ cDNA as described previously (Barrett et al. 2001), and AGRP and POMC probes were generated from cloned Siberian hamster cDNA fragments of $229 \mathrm{bp}$ and $344 \mathrm{bp}$ respectively (Mercer et al. 2000b) and have been validated in sheep brain (Adam et al. 2002). Briefly, sections were fixed, acetylated and hybridised overnight at $58^{\circ} \mathrm{C}$ using 35S-labelled cRNA probes $\left(1-1 \cdot 5 \times 10^{7}\right.$ c.p.m. $\left./ \mathrm{ml}\right)$. They were then treated with RNase A, desalted, with a final high stringency wash $(30 \mathrm{~min})$ in $0.5 \times \mathrm{SSC}$ at $60{ }^{\circ} \mathrm{C}$, dried and apposed to Hyperfilm $\beta$-max (Amersham Pharmacia Biotech UK Ltd, Little Chalfont, Bucks, UK). Intensity and total area of hybridisation over the ARC were quantified on autoradiographic images, using the Image-Pro Plus system (Media Cybernetics, Silver Spring, MD, USA). The integrated intensity of the hybridisation signal was then computed using standard curves generated from ${ }^{14} \mathrm{C}$ autoradiographic micro-scales (Amersham Pharmacia Biotech). For each probe, three to six sections from the medial hypothalamus (approximately $1.5-1.75 \mathrm{~mm}$ rostral to the opening of the third ventricle at the base of the hypothalamus just in front of the mamillary body) were analysed for each brain and the results averaged to give a single value for each animal. Within each experiment, all sections for a single probe were processed together and placed against the same sheet of autoradiographic film.

All reagents were obtained from Sigma unless otherwise stated.

\section{Statistical analysis}

LH secretory parameters were determined using Pulsefit software (supplied by R Kushler and M Brown, University of Michigan, Rochester, MI, USA). Groups were compared by two-way analysis of variance (using SigmaStat, experiment 1, or Minitab, experiment 2). Results are presented as means \pm S.E.M. and differences were considered significant at $P<0 \cdot 05$. 


\section{Results}

Food intake, BW, BCS and plasma metabolic status

Food intake, BW, BCS and plasma concentration measurements in the final week before the animals were killed were averaged to provide terminal values that were representative and temporally aligned with the hypothalamic neuropeptide gene expression analysis.

Experiment 1 (oestradiol-implanted castrates) Mean VFI was significantly higher in LDAL than SDAL $(P<0 \cdot 05)$ and lower in $\mathrm{R}$ than $\mathrm{AL}$ groups $(P<0 \cdot 001)$ (Fig. 1a). Mean terminal BW was greater in $A L$ than $R$ sheep within each photoperiod $(P<0 \cdot 001)$ but was greater in SD than LD sheep $(P<0 \cdot 001)$ (Fig. 1a). Mean BCS remained in the range $2-2 \cdot 25$ for all sheep and terminal values were not significantly different between the groups (data not shown).

Mean plasma leptin concentrations were higher in AL than $\mathrm{R}$ animals $(P<0 \cdot 01)$, but not significantly different between SD and LD. Plasma insulin concentrations were higher in AL than $\mathrm{R}$ sheep $(P<0 \cdot 01)$ and higher in $\mathrm{SD}$ than in LD $(P<0 \cdot 01)$ (Fig. 1a). There were no differences between photoperiod or intake groups in mean plasma glucose concentrations; mean plasma NEFA concentrations were higher in $\mathrm{R}$ than $\mathrm{AL}$ sheep within each photoperiod $(P<0 \cdot 05)$ and higher in SD than LD $(P<0 \cdot 05)$ (Fig. 1a).

Experiment 2 (rams) Mean VFI was twice as high in LDAL than in SDAL rams $(P<0 \cdot 001)$ and no different between SDR, SDAL and LDR groups (Fig. 1b). BW was initially higher in SD than LD groups following 'priming' in the opposite photoperiod. BW decreased in SDAL and SDR rams and increased in LDAL rams to reach similar terminal values across these three groups. BW of LDR sheep decreased during the experiment and was lower terminally than that of the other groups $(P<0 \cdot 05)$ (Fig. 1b). Terminal BCS was similar between SDAL and LDAL groups, but higher in SDAL than SDR (mean values $2 \cdot 62 \pm 0.085$ vs $2 \cdot 37 \pm 0 \cdot 085, P<0 \cdot 05)$ and in LDAL than LDR rams $(2 \cdot 50 \pm 0 \cdot 064$ vs $2 \cdot 25 \pm 0 \cdot 000, P<0 \cdot 05)$.

Plasma leptin concentrations were higher in LDAL than all of the other groups $(P<0 \cdot 01)$; insulin concentrations were lower in LDR rams than in all of the other groups $(P<0 \cdot 001$; Fig. 1 b). Both hormones were reduced by $\mathrm{R}$ in LD (leptin, $P<0.01$; insulin, $P<0 \cdot 001$ ) but not in SD (Fig. 1b). Plasma glucose was lower in SD than LD $(P<0 \cdot 001)$, with no effect of R; NEFA concentrations were elevated by $\mathrm{R}$ in both photoperiods $(P<0 \cdot 001)$, and were also elevated in SDAL compared with LDAL rams $(P<0 \cdot 001)$ (Fig. 1b).

\section{Reproductive status}

Experiment 1 (oestradiol-implanted castrates) Mean plasma LH concentration was higher in SD than LD sheep
Table 1 Paired testes weights ( $g$, means \pm S.E.M.) in rams kept for 12 weeks in LD or SD photoperiod with AL or R food (experiment 2, $n=6$ /group)

\begin{tabular}{llll} 
& \multicolumn{1}{l}{ AL } & & $\mathbf{R}$ \\
\cline { 2 - 2 } $\begin{array}{ll}\text { Photoperiod } \\
\text { LD }\end{array}$ & $220 \cdot 3 \pm 13 \cdot 34$ & & $184 \cdot 5 \pm 7 \cdot 95$ \\
SD & $368 \cdot 0 \pm 7 \cdot 75$ & & $348 \cdot 0 \pm 7 \cdot 93$ \\
& & \\
\hline
\end{tabular}

$(P<0.05)$ but similar between intake groups. Mean LH pulse frequency was unaffected by photoperiod but higher in $\mathrm{AL}$ than $\mathrm{R}$ sheep $(P<0 \cdot 05)$. Mean LH pulse amplitude was not significantly affected by either photoperiod or intake, but baseline LH concentration was higher in SD than LD $(P<0 \cdot 05) \quad$ (Fig. 2a). There was no interaction between photoperiod and intake on LH secretory parameters.

Experiment 2 (rams) Mean plasma LH concentration was similar between photoperiod and intake groups. Mean LH pulse frequency was higher in SD than LD $(P<0 \cdot 001)$ but similar between intake groups within each photoperiod. Mean LH pulse amplitude and baseline were higher in LD than SD $(P<0.05$ and $P<0.01$ respectively $)$ but similar between intake groups (Fig. 2b). Mean weight of testes when the animals were killed was higher in SD than LD rams $(P<0 \cdot 001)$ with no significant effect of intake (Table 1).

\section{Hypothalamic ARC gene expression}

Experiment 1 (oestradiol-implanted castrates) OB-Rb gene expression levels were highly variable and were not significantly different between the groups (Fig. 3a). R increased amounts of NPY $(P<0.01)$ and AGRP gene expression $(P<0 \cdot 05)$, with no effect of photoperiod (Fig. 3a). POMC gene expression was not different between photoperiods or intake groups (Fig. 3a).

Experiment 2 (rams) OB-Rb gene expression in the ARC was increased by $\mathrm{R}(P<0 \cdot 001)$, with no effect of photoperiod (Fig. 3b). NPY and AGRP mRNAs were increased by $\mathrm{R}$ in $\mathrm{LD}(P<0 \cdot 001)$ but not in $\mathrm{SD}$; there was no effect of photoperiod alone on NPY gene expression, but AGRP gene expression was higher in LD than SD $(P<0 \cdot 01)$ (Figs $3 \mathrm{~b}$ and 4$)$. POMC gene expression was higher in SDAL than LDAL $(P<0 \cdot 05)$, and was decreased by $\mathrm{R}$ in $\mathrm{SD}$ but not in $\mathrm{LD}(P<0 \cdot 05)$. CART gene expression in the ARC was higher in SD than LD $(P<0 \cdot 05)$, and there was no effect of $\mathrm{R}$ (Figs $3 \mathrm{~b}$ and 4$)$.

\section{Discussion}

Photoperiod treatment alone induced changes in appetite, with VFI higher in LD and lower in SD in both rams and 
(a)
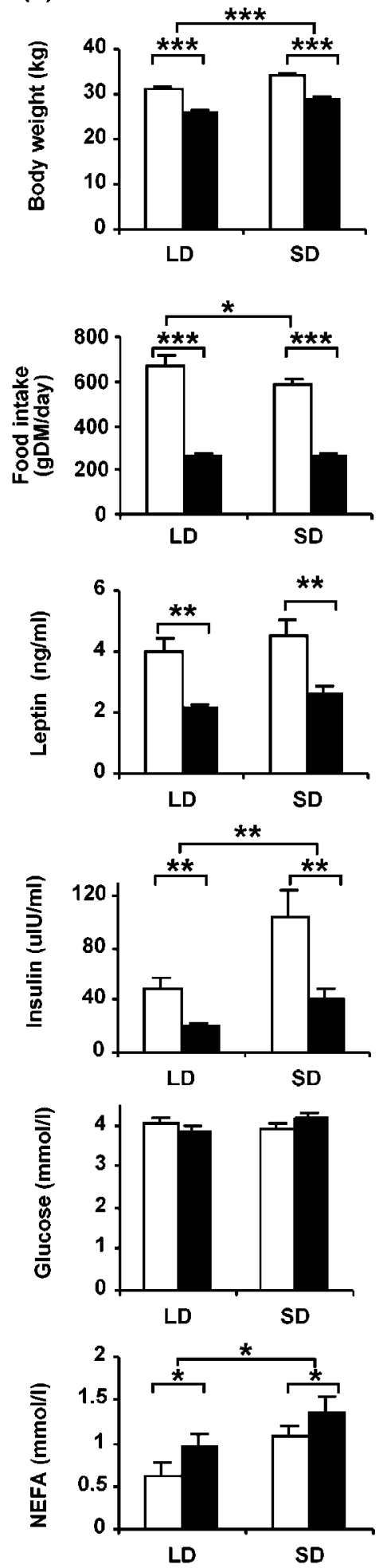

(b)
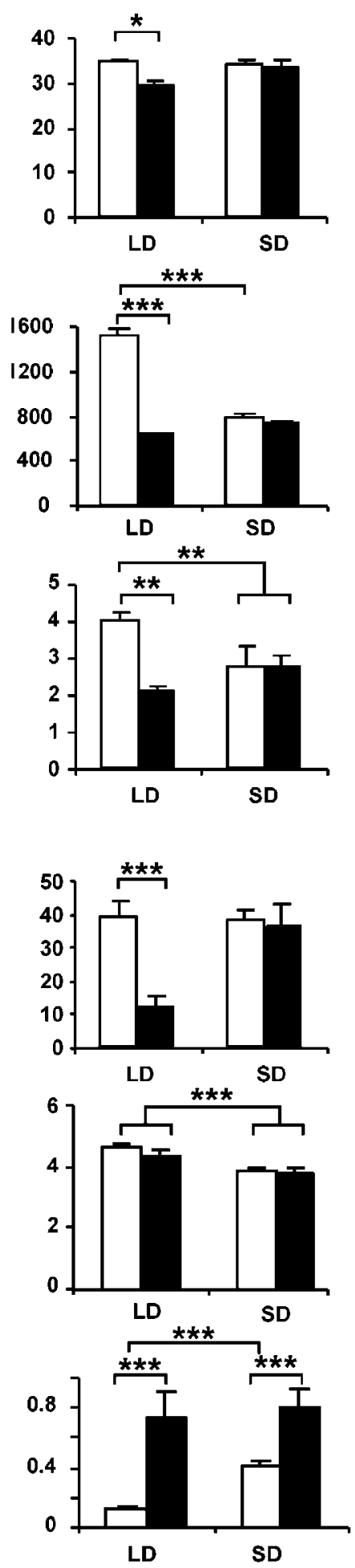

Figure 1 BW, food intake and plasma concentration of leptin, insulin, glucose and NEFA in sheep kept in LD or SD photoperiod with AL (open bars) or $\mathrm{R}$ (solid bars) food: (a) oestradiol-implanted castrates (11 weeks, experiment 1) and (b) rams (12 weeks, experiment 2). ${ }^{*} P<0 \cdot 05,{ }^{* *} P<0 \cdot 01,{ }^{* * *} P<0 \cdot 001$. Values are means \pm S.E.M. 
(a)
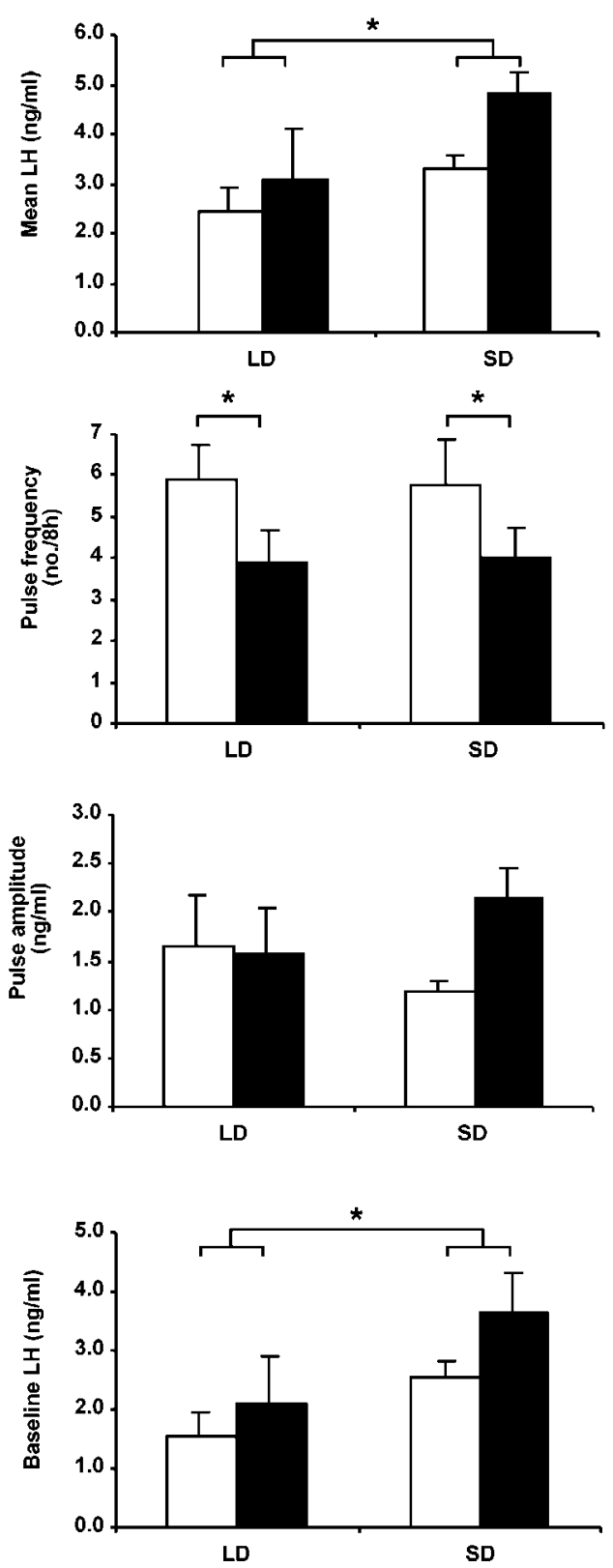

(b)
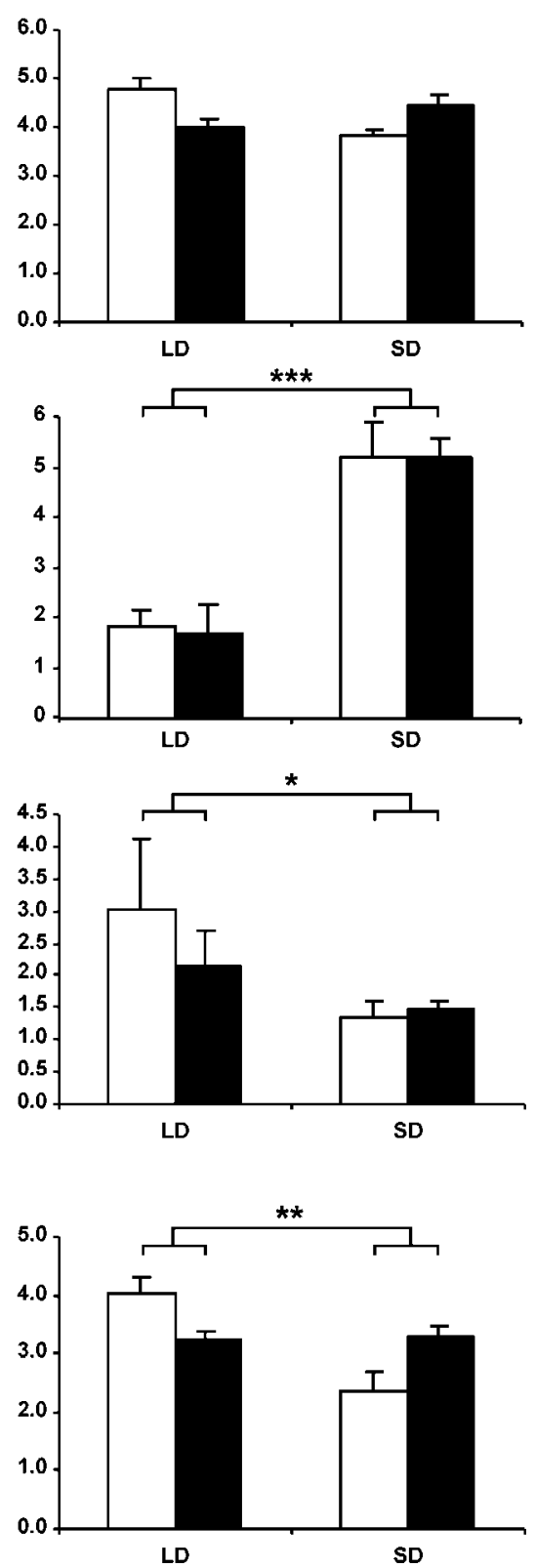

Figure 2 Plasma LH secretory parameters in sheep kept in LD or SD photoperiod with AL (open bars) or R (solid bars) food: (a) oestradiol-implanted castrates (11 weeks, experiment 1 ) and (b) rams (12 weeks, experiment 2). ${ }^{*} P<0 \cdot 05,{ }^{* *} P<0 \cdot 01,{ }^{* * *} P<0 \cdot 001$. Values are means \pm S.E.M.

oestradiol-implanted castrates, as expected (Kay 1985). Importantly, these AL-feeding animals were satiated in both photoperiods and this was generally reflected in their plasma metabolic profiles. In both experiments, plasma NEFA concentrations were lower in LD, indicative of an anabolic state, and higher in SD, indicative of catabolism and mobilisation of fat reserves. Terminal plasma leptin and glucose concentrations in experiment 2 (rams) were higher in LD than SD, although insulin values and BW were similar in both photoperiods. However, in experiment 1 (oestradiol-implanted castrates), plasma leptin and glucose values were not different between the photoperiods, and both plasma insulin concentrations and BW remained higher in $\mathrm{SD}$ than $\mathrm{LD}$. These data indicated that 
(a)
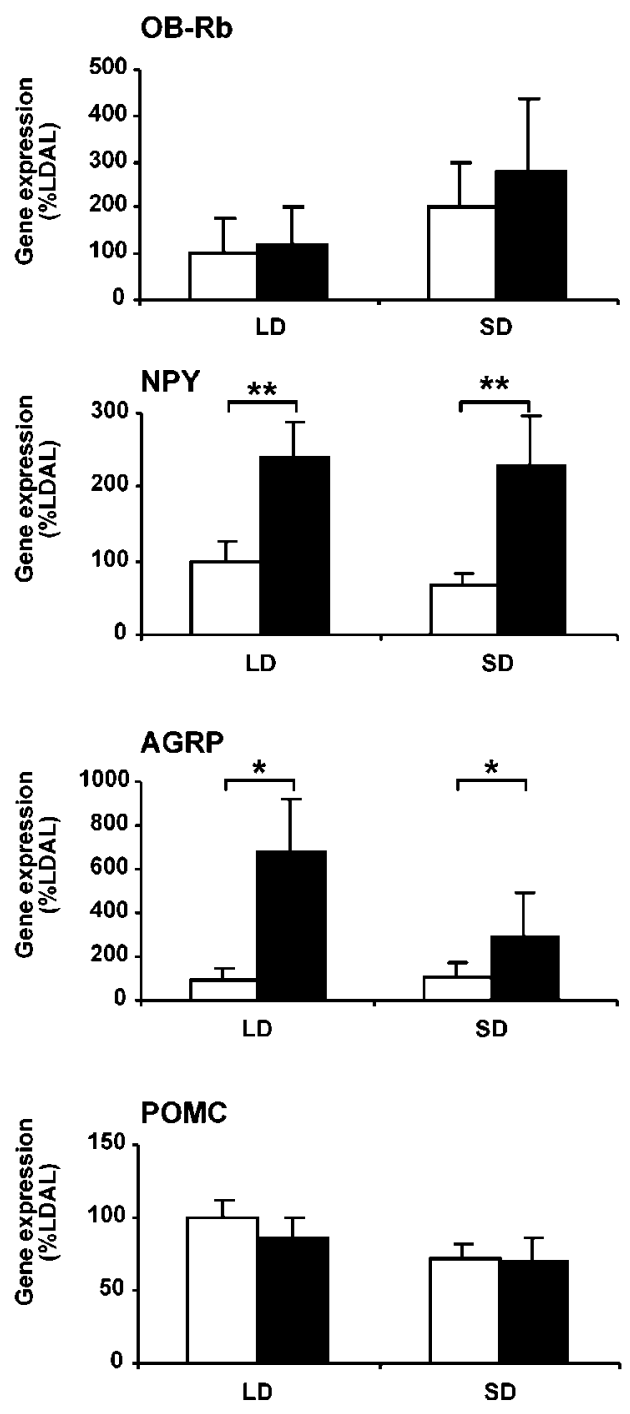

(b)

OB-Rb
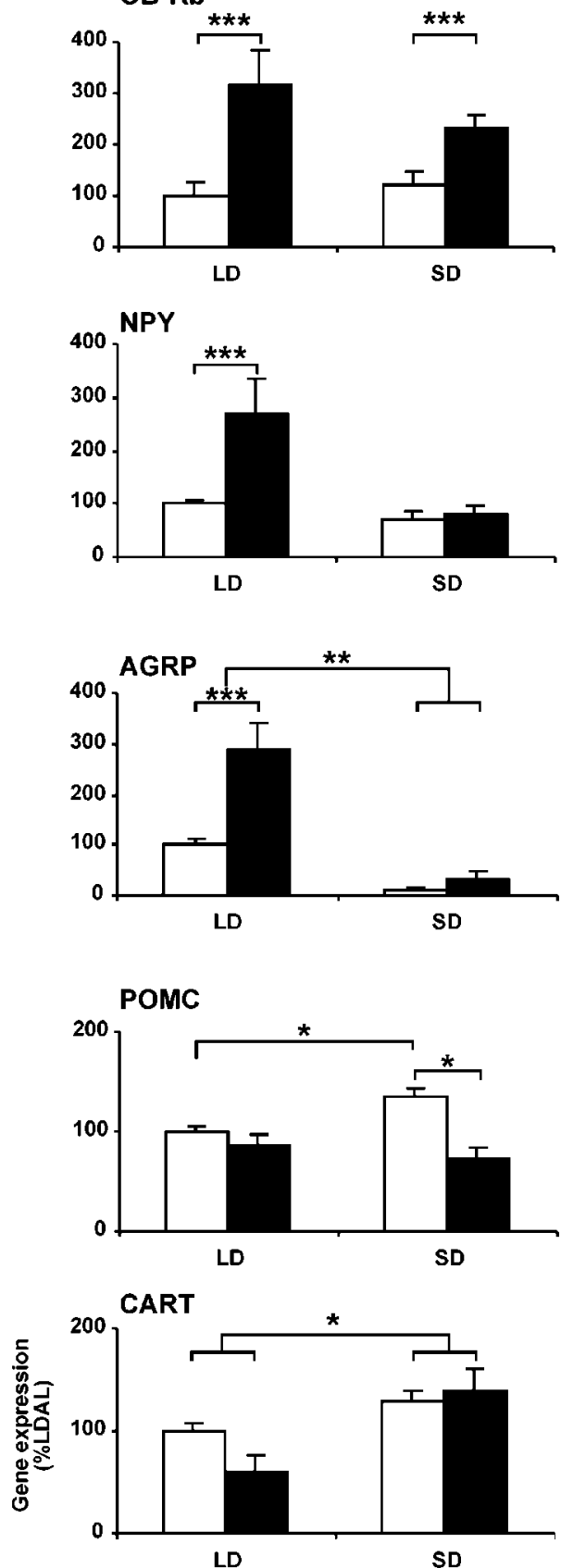

Figure 3 Gene expression for OB-Rb, NPY, AGRP, POMC and CART in the ARC of sheep kept in LD or SD photoperiod with $\mathrm{AL}$ (open bars) or R (solid bars) food: (a) oestradiol-implanted castrates (experiment 1) and (b) rams (experiment 2). ${ }^{*} P<0 \cdot 05,{ }^{*} P<0 \cdot 01,{ }^{* *} P<0 \cdot 001$. Values are means \pm S.E.M.

the contrasting anabolic and catabolic photoperiodic phenotypes were less well established in experiment 1 (without priming in the opposite photoperiod) than in experiment 2 (with priming). In contrast to photoperiod treatment alone, food restriction caused BW loss in both photoperiods in both experiments. The restricted animals were clearly unsatiated, mobilising body reserves (with increased plasma NEFA in all $\mathrm{R}$ groups compared with 

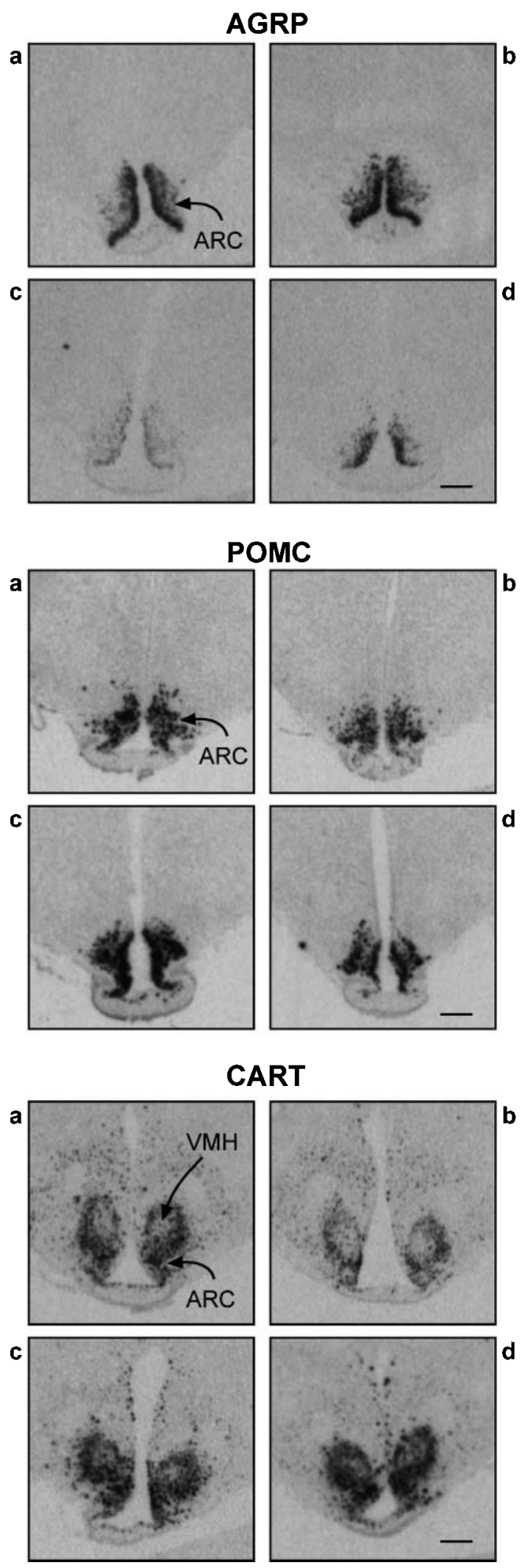

their respective AL groups) and with reduced circulating insulin and leptin (except in the more mildly restricted experiment 2 SDR rams) but with glucose levels maintained. Thus altogether there were clear differences in nutritional state between the groups of animals against which to compare the activities of nutritionally sensitive, appetite-regulating hypothalamic pathways. In addition, these groups had either a constant low level of oestradiol feedback (experiment 1, oestradiol-implanted castrates) or, as indicated by the differences in testis size (Lincoln \& Davidson 1977), high circulating testosterone in SD and low testosterone in LD (experiment 2 rams).

Photoperiod treatment alone had no effect on OB-Rb gene expression in either experiment. This was despite elevated plasma leptin in LD in experiment 2, although it could perhaps be explained in experiment 1 by the lack of significant difference in circulating leptin between the photoperiods. However, the rams of Clarke et al. (2003) also showed no differences in plasma leptin between the photoperiods, yet had up-regulated $\mathrm{OB}-\mathrm{Rb} \mathrm{mRNA}$ in LD. In contrast, male Siberian hamsters in LD have both increased circulating leptin and up-regulated OB-Rb mRNA in the ARC (Mercer et al. 2001). The foregoing observations suggest that photoperiod can override the effects of systemic leptin concentration on hypothalamic expression of its receptor and that photoperiod may directly influence leptin receptor gene expression. Furthermore, the decrease in plasma leptin as a result of food restriction had no significant effect on OB-Rb mRNA in experiment 1 whereas it was associated with increased $\mathrm{OB}-\mathrm{Rb}$ gene expression in LD in experiment 2 as expected (Mercer et al. 2001). However, the increase in $\mathrm{OB}-\mathrm{Rb}$ gene expression induced by food restriction in SD in experiment 2 was not associated with decreased plasma leptin, again suggesting dissociation of the ligand-receptor relationship. Nonetheless, it appears from experiment 2 that $\mathrm{OB}-\mathrm{Rb}$ expression levels are not up-regulated by low circulating leptin brought about by photoperiod-induced change in nutritional status but they are up-regulated when low circulating leptin is induced by food restriction. Overall, the findings support the hypothesis that hypothalamic OB-Rb gene expression responses to leptin feedback are regulated by photoperiod. There was no evidence that $\mathrm{OB}-\mathrm{Rb}$ gene expression was affected by gonadal steroids.

Photoperiod treatment alone had no effect on NPY gene expression in either oestradiol-implanted castrates

Figure 4 Typical coronal hypothalamic autoradiographs showing gene expression in the ARC for AGRP, POMC and CART in rams kept for 12 weeks in ( $a$ and b) LD or (c and d) SD photoperiod with ( $a$ and c) AL or ( $b$ and d) R food (experiment 2). AGRP gene expression is higher in LD than SD and is increased by R; POMC gene expression is higher in SD than LD and is decreased by $\mathrm{R}$ only in SD; CART gene expression is higher in SD than LD, with no effect of $\mathrm{R}$. $\mathrm{VMH}=$ ventromedial hypothalamic nucleus. Bar $=1 \mathrm{~mm}$. 
(experiment 1) or rams (experiment 2). Similar results are seen in freely feeding Siberian hamsters (Adam et al. 2000, Mercer et al. 2001); however, Clarke et al. (2003) reported that amounts of NPY mRNA were higher in LD than SD rams. Reasons for the apparently conflicting results from the two sheep studies may include differences in the duration of photoperiod exposure used (18 weeks in Clarke et al. (2003) and 11-12 weeks in the present study) and differences in the methodologies employed; i.e. Clarke et al. (2003) used perfused brains whereas the present brains were frozen, and the in situ hybridisation signal was analysed in photographic emulsion-dipped sections in the former study by counting silver grains at the cellular level whereas we analysed the signal by film autoradiography and optical densitometry measurements at the level of the whole hypothalamic nucleus. Nonetheless, in both photoperiods in experiment 1 and in LD in experiment 2, orexigenic NPY gene expression was up-regulated by imposed food restriction, in agreement with previous findings (Adam et al. 1997), and the lack of NPY up-regulation in SDR in experiment 2 probably reflected the lack of severity of the food restriction, which had not altered the circulating leptin concentrations unlike the other restriction treatments. Circulating leptin appeared to be inversely related to corresponding NPY gene expression data in the $\mathrm{AL}$ vs $\mathrm{R}$ comparison, consistent with leptin feedback regulating NPY (e.g. Henry et al. 1999); however, this relationship breaks down when comparing the LDR and SDAL rams in experiment 2. They had similar food intake and plasma leptin and yet NPY gene expression was up-regulated in the presence of reduced leptin caused by the food restriction but not in the presence of the leptin signal of similar magnitude induced by SD. This would indicate that NPY neurones are somehow primed to anticipate and not react to reduced nutritional (or leptin) feedback during SD. Conversely, the difference in NPY gene expression between the photoperiods was not accompanied by differences in circulating leptin in the rams of Clarke et al. (2003). Both scenarios are consistent with photoperiod feedback overriding nutritional (leptin) feedback in regulating NPY gene expression. Similarly, the decrease in plasma insulin in the food-restricted animals could also have been causally related to the increase in NPY gene expression (Schwartz et al. 1992), yet the decreased plasma insulin seen in the AL-fed LD vs SD oestradiol-implanted castrates was not associated with altered NPY gene expression. Finally, NPY gene expression was not affected by gonadal steroid status in the present animals.

ARC gene expression for the orexigenic endogenous melanocortin antagonist AGRP was up-regulated by $\mathrm{R}$ in both experiments (except in the more mildly restricted SDR group in experiment 2) in agreement with earlier findings (Henry et al. 2001). AGRP mRNA was also up-regulated by LD in the rams (experiment 2), in agreement with Clarke et al. (2003), but not in the oestradiol-implanted castrates (experiment 1). This indicated that testosterone, circulating concentrations of which would have been elevated in SD given the increased testis size (Lincoln \& Davidson 1977), might be either directly down-regulating AGRP gene expression or indirectly facilitating down-regulation of AGRP by SD. Such an effect of testosterone has not been reported in the literature but it is noteworthy that AGRP gene expression is conversely decreased in male Siberian hamsters in LD when their circulating testosterone is highest (Mercer et al. 2000b). Furthermore, AGRP gene expression was decreased in SD hamsters given subcutaneous implants to raise systemic testosterone concentrations (J G Mercer, personal communication) and AGRP gene expression is apparently not regulated by photoperiod in female Siberian hamsters (Adam et al. 2000). It is therefore tempting to speculate that testosterone inhibition of orexigenic AGRP may contribute to the greater amplitude of photoperiod-induced appetite cycles seen in rams compared with castrates (Kay 1985). Similarly, there was a clear influence of testosterone (in this case stimulatory) on ARC gene expression for POMC, the precursor for the anorexigenic peptide $\alpha$-melanocytestimulating hormone. POMC mRNA was up-regulated in $\mathrm{SD}$ in the reproductively active rams (in agreement with Clarke et al. 2003) but not in the oestradiolimplanted castrates; it is also up-regulated in LD in Siberian hamsters when they are reproductively active (Mercer et al. 2001). Consistent with these data, Hileman et al. (1998) reported ARC POMC mRNA to be down-regulated in LD in castrated sheep but only in those with testosterone replacement, suggesting that testosterone amplifies the POMC response to photoperiod. It is tempting to speculate that the melanocortin pathway may be implicated in driving photoperiodinduced appetite cycles in the ram and/or in mediating the testosterone amplification of these cycles. In addition, the present data indicated that testosterone might also be implicated in amplifying the POMC response to negative energy balance, since POMC mRNA was down-regulated by $\mathrm{R}$ compared with AL, in agreement with published sheep data (McShane et al. 1993), but this response was seen only in rams and only in SD.

Gene expression for the anorexigenic neuropeptide CART was up-regulated in the ARC of the SD (reproductively active) rams. In our laboratory, up-regulation of CART mRNA is a consistent finding in SD (reproductively inactive) Siberian hamsters of both sexes and at different ages (Adam et al. 2000, Mercer et al. 2003). It is unlikely therefore that photoperiod-induced changes in CART are affected by changes in gonadal steroids, and it is probable that CART mRNA was also elevated in SD in the castrates of experiment 1 . CART gene expression in the ARC was not affected by food restriction in either 
photoperiod, and overall the data are consistent with a role for CART in mediating the anorexic response to SD (Mercer et al. 2003).

The characteristic photoperiod effects on the reproductive neuroendocrine axis were clearly expressed in rams, with LH pulse frequency (and GnRH by inference) markedly increased in SD, but there was no effect of food restriction in either LD (with low circulating testosterone) or SD (with high testosterone). Although oestradiolimplanted castrates had increased LH output in SD, this was not attributable to an increase in pulse frequency, suggesting a reduced intra-hypothalamic influence of photoperiod on $\mathrm{GnRH}$ pulsatile secretion compared with rams. These data are consistent with amplification by the increased concentration of gonadal steroids of SD stimulation of the reproductive neuroendocrine axis in rams, and this axis therefore appears more sensitive to photoperiod in rams than in oestradiol-implanted castrates. Conversely, the data also indicated that sensitivity of the reproductive neuroendocrine axis to nutritional feedback is increased in oestradiol-implanted castrates compared with rams. Food restriction reduced LH pulse frequency in the oestradiolimplanted castrates but not in the rams, irrespective of photoperiod, supporting the hypothesis that oestradiol sensitises the reproductive neuroendocrine axis to altered nutritional feedback (Foster \& Olster 1985, Beckett et al. 1997). In the more photosensitive rams, decreased nutritional feedback could not override photoperiodic regulation of reproductive neuroendocrine output. Thus, there was no evidence for photoperiodic regulation of the reproductive neuroendocrine response to nutritional feedback, irrespective of gonadal steroid status, but gonadal steroid status clearly influenced photoperiodic and nutritional effects on appetite-regulating hypothalamic pathways.

Overall these data are consistent with a causal role for CART in SD-induced anorexia in seasonal animals (Mercer et al. 2003) and with a novel role for testosterone interacting with the melanocortin pathway to amplify SD anorexia in rams. The results support the hypothesis that the sheep hypothalamus responds differently to voluntary photoperiod-induced changes in nutritional feedback as opposed to imposed changes in nutritional feedback induced by food restriction in terms of gene expression for appetite-regulating hypothalamic neuropeptides, and these responses were influenced by gonadal steroid status.

\section{Acknowledgements}

This research was supported by the Scottish Executive Environment and Rural Affairs Department. Z A A was in receipt of a Boyd Orr Research Council studentship. Thanks go to animal house and veterinary staff at the Rowett Research Institute and the Macaulay Institute for routine animal care, A Parlow (NIDDK) for LH antibody and peptide, A Gertler for ovine leptin peptide, L Thomas for leptin antibody, M Marie for leptin analyses in experiment 1, $\mathrm{T}$ Atkinson for iodinations, $\mathrm{M}$ Annand for automated glucose and NEFA analyses, K Sinclair for oestradiol determinations, and J Mercer, N Hoggard, P Barrett, A Ross and S Sabol for riboprobes.

\section{References}

Adam CL 2000 Nutritional and photoperiodic regulation of appetite and reproduction in seasonal domestic mammals. Reproduction in Domestic Animals 6 (Suppl) 1-8.

Adam CL \& Findlay PA 1998 Inhibition of luteinizing hormone secretion and expression of $\mathrm{c}$-fos and corticotrophin-releasing factor genes in the paraventricular nucleus during insulin-induced hypoglycaemia in sheep. Journal of Neuroendocrinology 10 777-783.

Adam CL, Findlay PA, Kyle CE, Young P \& Mercer JG 1997 Effect of chronic food restriction on pulsatile luteinizing hormone secretion and hypothalamic neuropeptide $\mathrm{Y}$ gene expression in castrate male sheep. Journal of Endrocrinology 152 329-337.

Adam CL, Moar KM, Logie TJ, Ross AW, Barrett P, Morgan PJ \& Mercer JG 2000 Photoperiod regulates growth, puberty and hypothalamic neuropeptide and receptor gene expression in female Siberian hamsters. Endocrinology 141 4349-4356.

Adam CL, Archer ZA, Findlay PA, Thomas L \& Marie M 2002 Hypothalamic gene expression in sheep for cocaine- and amphetamine-regulated transcript, pro-opiomelanocortin, neuropeptide $\mathrm{Y}$, agouti-related peptide and leptin receptor, and responses to negative energy balance. Neuroendocrinology $\mathbf{7 5}$ 250-256.

Ahima RS, Saper, CB, Klier JS \& Elmquist JK 2000 Leptin regulation of neuroendocrine systems. Frontiers of Neuroendocrinology 21 263-307.

Archer ZA, Rhind SM, Findlay PA, Kyle CE, Thomas L \& Adam CL 2002 Contrasting effects of constant body adiposity and increasing food intake on LH secretion and hypothalamic gene expression in sheep. Journal of Endocrinology 175 383-393.

Barrett P, Morris MA, Moar KM, Mercer JG, Davidison JA, Findlay PA, Adam CL \& Morgan PJ 2001 The differential regulation of CART gene expression in a pituitary cell line and primary cell cultures of ovine pars tuberalis cells. Journal of Neuroendocrinology 13 347-352.

Beckett JL, Sakurai H, Famula TR \& Adams TE 1997 Negative feedback potency of estradiol is increased in orchidectomized sheep during chronic nutrient restriction. Biology of Reproduction $\mathbf{5 7}$ 408-414.

Clarke IJ \& Cummins JT 1982 The temporal relationship between gonadotropin releasing hormone $(\mathrm{GnRH})$ and luteinizing hormone (LH) secretion in ovariectomized ewes. Endocrinology 111 1449-1455.

Clarke IJ, Tilbrook AJ, Turner AI, Doughton BW \& Goding JW 2001 Sex, fat and the tilt of the earth: effects of sex and season on the feeding response to centrally administered leptin in sheep. Endocrinology 142 2725-2728.

Clarke IJ, Rao A, Chilliard Y, Delavaud C \& Lincoln GA 2003 Photoperiod effects on gene expression for hypothalamic appetite-regulating peptides and food intake in the ram. American Journal of Physiology 284 R101-R115.

Foster DL \& Olster DH 1985 Effect of restricted nutrition on puberty in the lamb: patterns of tonic luteinizing hormone ( $\mathrm{LH})$ secretion and competency of the LH surge system. Endocrinology 116 375-381.

Goodman RL 1994 Neuroendocrine control of the ovine estrous cycle. In The Physiology of Reproduction, edn 2, pp 659-709. Eds E Knobil \& JD Neill. New York: Raven. 
Henry BA, Goding JW, Alexander WS, Tilbrook AJ, Canny BJ, Dunshea F, Rao A, Mansell A \& Clarke IJ 1999 Central administration of leptin to ovariectomized ewes inhibits food intake without affecting the secretion of hormones from the pituitary gland: evidence for a dissociation of effects on appetite and neuroendocrine function. Endocrinology 140 1175-1182.

Henry BA, Tilbrook AJ, Dunshea FR, Rao A, Blache D, Martin GB \& Clarke IJ 2000 Long-term alterations in adiposity affect the expression of melanin-concentrating hormone and enkephalin but not proopiomelanocortin in the hypothalamus of ovariectomized ewes. Endocrinology 141 1506-1514.

Henry BA, Rao A, Ikenasio BA, Mountjoy KG, Tilbrook AJ \& Clarke IJ 2001 Differential expression of cocaine- and amphetamine-regulated transcript and agouti related-protein in chronically food-restricted sheep. Brain Research 918 40-50.

Hileman SM, Kuehl DE \& Jackson GL 1998 Photoperiod affects the ability of testosterone to alter proopiomelanocortin mRNA, but not luteinizing hormone-releasing hormone mRNA, levels in male sheep. Journal of Neuroendocrinology 10 587-592.

I'Anson H, Foster DL, Foxcroft GR \& Booth PJ 1991 Nutrition and reproduction. Oxford Reviews of Reproductive Biology 13 239-311.

Kay RNB 1985 Seasonal variation of appetite in ruminants. In Recent Advances in Animal Nutrition, pp 199-210. Ed. W Haresign. London: Butterworths.

Lincoln GA \& Davidson W 1977 The relationship between sexual and aggressive behaviour, and pituitary and testicular activity during the seasonal sexual cycle of rams and the influence of photoperiod. Journal of Reproduction and Fertility 49 267-276.

Lincoln GA \& Short RV 1980 Seasonal breeding: nature's contraceptive. Recent Progress in Hormone Research 36 1-52.

Lincoln GA \& Richardson M 1998 Photo-neuroendocrine control of seasonal cycles in body weight, pelage growth and reproduction: lessons from the HPD sheep model. Comparative Biochemistry and Physiology 119C 283-294.

McNeilly AS, Jonassen JA \& Fraser HM 1986 Suppression of follicular development after chronic LHRH immunoneutralization in the ewe. Journal of Reproduction and Fertility 76 481-490.

MacRae JC, Bruce LA, Hovell FDDeB, Hart IC, Inkster J, Walker A \& Atkinson T 1991 Influences of protein nutrition on the response of growing lambs to exogenous bovine growth hormone. Journal of Endocrinology 130 53-61.

McShane TM, Petersen SL, McCrone S \& Keisler DH 1993 Influence of food restriction on neuropeptide-Y, proopiomelanocortin, and luteinizing hormone-releasing hormone gene expression in sheep hypothalami. Biology of Reproduction $\mathbf{4 9}$ 831-839.
Mann GE, Lamming GE \& Fray MD 1995 Plasma oestradiol and progesterone during early pregnancy in the cow and the effects of treatment with buserelin. Animal Reproduction Science 37 121-131.

Marie M, Findlay PA, Thomas L \& Adam CL 2001 Daily patterns of plasma leptin in sheep: effects of photoperiod and food intake. Journal of Endocrinology 170 277-286.

Mercer JG, Lawrence CB, Beck B, Burlet A, Atkinson T \& Barrett P 1995 Hypothalamic NPY and preproNPY mRNA in Djungarian hamsters: effects of food deprivation and photoperiod. American Journal of Physiology 269 R1099-R1106.

Mercer JG, Moar KM, Findlay PA, Hoggard N \& Adam CL 1998 Association of leptin receptor (OB-Rb), NPY and GLP-1 in the ovine and murine brainstem. Regulatory Peptides 75 271-278.

Mercer JG, Adam CL \& Morgan PJ 2000a Towards an understanding of physiological body weight regulation: seasonal animal models. Nutritional Neuroscience 3 307-320.

Mercer JG, Moar KM, Ross AW, Hoggard N \& Morgan PJ $2000 b$ Photoperiod regulates arcuate nucleus POMC, AGRP, and leptin receptor mRNA in Siberian hamster hypothalamus. American Journal of Physiology 278 R271-R281.

Mercer JG, Moar KM, Logie TJ, Findlay PA, Adam CL \& Morgan PJ 2001 Seasonally-inappropriate body weight induced by food restriction: effect on hypothalamic gene expression in male Siberian hamsters. Endocrinology 142 4173-4181.

Mercer JG, Ellis C, Moar KM, Logie TJ, Morgan PJ \& Adam CL 2003 Early regulation of hypothalamic arcuate nucleus CART gene expression by photoperiod in Siberian hamsters. Regulatory Peptides 111 129-136.

Miller DW, Findlay PA, Morrison MA, Raver N \& Adam CL 2002 Seasonal and dose-dependent effects of intracerebroventricular leptin on luteinising hormone secretion and appetite in sheep. Journal of Endocrinology 175 395-404.

Robinson JJ 1983 Nutrition of the pregnant ewe. In Sheep Production, pp 111-113. Ed. W Haresign. London: Butterworths.

Russel AJF, Doney JM \& Gunn RG 1969 Subjective assessment of body fat in live sheep. Journal of Agricultural Science 72 451-454.

Schwartz MW, Sipols AJ, Marks JL, Sanacora G, White JD, Scheurink A, Kahn SE, Baskin DG, Woods SC, Figlewicz DP \& Porte D Jr 1992 Inhibition of hypothalamic neuropeptide Y gene expression by insulin. Endocrinology 130 3608-3616.

Received in final form 4 June 2004

Accepted 10 June 2004

Made available online as an

Accepted Preprint 18 June 2004 